\title{
Modeling and Analysis of a Micro Gas Turbine Fuelled with Hydrogen and Natural Gas Blends
}

\author{
Shahrokh Barati ${ }^{1 *}$, Livio De Santoli ${ }^{1}$, and Gianluigi Lo Basso ${ }^{l}$ \\ ${ }^{1}$ DIAEE-Department of Astronautics Electrical Energy Engineering, Sapienza, University of \\ Rome, Via Eudossiana 18, Rome 00184, Italy
}

\begin{abstract}
This study deals with implementing an analytical model to simulate the energy performance associated with a Micro Gas Turbine when $\mathrm{H}_{2} \mathrm{NG}$ (Hydrogen Enriched Natural Gas) blends are used as fuel. The experimental campaign validated the simulation results at the actual operating conditions of the Micro Gas Turbine. The experimental campaign for model validation has been carried out over the spring and summer periods. Additionally, the MGT performance has been detected when fuelled $\mathrm{H}_{2} \mathrm{NG}$ with hydrogen fraction ranges between $0 \%$ vol. to $10 \%$ vol., with a $2 \%$ vol. Step., according to the main findings, the fuel consumption is reduced significantly. Also, heat recovery and electrical reliability improve slightly even though environmental factors influence the system. A numerical model was developed with MATLAB-Simulink to model the operation of the MGT. Thus, the relative standard errors affecting the main output parameters have been determined.
\end{abstract}

\section{Introduction}

Climate change is a globally recognized problem and mitigating it has been identified as one of the most significant challenges. The way to solve this problem is to reduce greenhouse gas (GHG) emissions by decarbonizing the energy system with renewable energies [1-2]. It is critical that the energy used is safe, reliable, competitive, locally generated, and sustainable [3]. Several methods can be used to utilize renewable energy sources, including wind energy and solar energy [4]. Although both technologies have enormous potential and will become more prevalent in the coming years, their applications present new challenges [5]. Another way to store electricity is to use hydrogen as an energy carrier through a process called Power to Gas. Electricity is converted into hydrogen by electrolysis of water and can be

\footnotetext{
* Corresponding author: shahrokh.barati@uniroma1.it
} 
stored in pressure tanks or metal hydride tanks [6-7]. Hydrogen can be used in a variety of ways, one of the most generally recognized use is as an energy carrier for transportation [8-9]. Constrisciani et al. [10] introduced the concept of hydro methane to describe a mixture of methane and hydrogen with a hydrogen content of 5 to $30 \%$. Hydrogen burns more quickly than pure natural gas, compared to methane. It is currently a good idea to promote improved combustion methods for hydrocarbon fuels mixed with hydrogen gas in gas turbine applications [11]. Rajpara et al [12] investigated the emission properties of a $\mathrm{CH}_{4} / \mathrm{H}_{2}$ mixture in a combustion chamber and observed that the addition of hydrogen increases the flame temperature, reduces the flame dimensions and thus CO. Other studies [13] focused on the thermoeconomic evaluation of a new integrated CHP system integrating solar energy-based technologies, a biogas-steam reformer with methanol, and hydrogen generation. Ouchikh et al. [14] investigated of the influence of hydrogen enrichment in natural gas on the combustion parameters of a dual-fuel diesel engine. Cappelletti et al. [15] described a numerical redesign of a $100 \mathrm{~kW}$ MGT combustion chamber for 100 percent hydrogen and showed that a hydrogen-powered combustion chamber produces more $\mathrm{NOx}$ than a $\mathrm{CH}_{4}$ combustion chamber, but combustion with hydrogen enables the combustion chamber to operate in lean conditions. De Santoli et al. [16] carried out the potential use of $\mathrm{H}_{2} \mathrm{NG}$ blends in established technologies such as internal combustion engines to evaluate the application's strengths and weaknesses. Furthermore, based on an experimental campaign, Lo Basso et al. [17] presented their findings on the impacts of $\mathrm{H}_{2}$ addition up to $15 \% \mathrm{vol}$. in the fuel mix on the electrical and heat recovery efficiency, as well as pollution emissions of a condensing microCHP. De Santoli et al. [18] studied the seasonal energy and environmental characterization of a commercial micro gas turbine fuelled with hydrogen enriched natural gas blends. According to several authors, CHP technology can provide environmental and economic benefits by reducing energy consumption in buildings [19-21]. Several research projects are currently being implemented to develop possible environmentally friendly fuels. Among gaseous fuels, a recent study showed that burning $\mathrm{H}_{2} \mathrm{NG}$ produces lower $\mathrm{CO}$ and $\mathrm{CO}_{2}$ emissions than any other gaseous fuel [22]. Since the hydrogen-enhanced mixtures burn at a faster laminar speed and have a greater $\mathrm{H} / \mathrm{C}$ ratio, a reduction in carbon emissions may be achieved [23]. The purpose of this research is modeling, and analysis performance of a commercial Micro Gas Turbine fuelled with Hydrogen and Natural Gas blends based on experimental data. The key findings are presented in this paper.

\section{Test rig description and methodology}

The aim of this research is to model a micro gas turbine fuelled with hydrogen and natural gas blends. The data for the modeling were carried out in the experimental campaign DIAEE (Department of Astronautical, Electrical and Energy Engineering) of the university of Sapienza in Rome. MGT was manufactured by Capstone Corporation and has power and heat ratings of $30 \mathrm{KWel}$ and $63 \mathrm{KWth}$, respectively. The data obtained from a series of experiments in which the hydrogen content in the fuel was gradually increased. The electrolyte is made directly in the laboratory using an alkaline electrolyser. MGTs are small power generation systems (less than 500 $\mathrm{kWel}$ ) based on the Brayton cycle. The main difference between high performance gas turbines and micro gas turbines is that high performance gas turbines are based 
on the recovery cycle and are equipped with turbo-radial machines. On this research, the Capstone C30 micro gas turbine was used. Table 1 shows the main technical characteristics of the tested machine.

Table 1. Capstone C30 datasheet

\begin{tabular}{|l|l|}
\hline \multicolumn{1}{|c|}{ Parameters } & \multicolumn{1}{c|}{ Values } \\
\hline Engine type & Natural gas Micro Turbine \\
\hline Rotational speed & $96,000 \mathrm{rpm}$ \\
\hline Compression ratio & $4: 1$ \\
\hline Gross Active power & $30 \mathrm{~kW}$ \\
\hline Width & $0.76 \mathrm{~m}$ \\
\hline Depth & $1.5 \mathrm{~m}$ \\
\hline Height & $1.8 \mathrm{~m}$ \\
\hline Weight & $\mathrm{Grid} \mathrm{Connect} \mathrm{-} \mathrm{405} \mathrm{kg}$ \\
\hline Net Active Power & $28 \mathrm{~kW}$ \\
\hline Voltage & $400-480 \mathrm{~V}$, AC, PPPN \\
\hline Frequency & $50-60 \mathrm{~Hz}(\mathrm{Grid}$ Connected $)$ \\
\hline CHP electric efficiency (based on LHV) & 0.26 \\
\hline CHP heat recovery efficiency (based on LHV) & 0.58 \\
\hline Max. thermal output power & $60 \mathrm{~kW}$ \\
\hline Hot water flow & $2.9 \mathrm{~m} / \mathrm{h}$ \\
\hline Exhaust Temperature & $275^{\circ} \mathrm{C}\left(530^{\circ} \mathrm{F}\right)$ \\
\hline Exhaust Gas Flow & $0.31 \mathrm{~kg} / \mathrm{s}$ \\
\hline Max. operating pressure & $6 \mathrm{bar}$ \\
\hline Average fuel consumption & $11 \mathrm{Nm} 3 / \mathrm{h}$ \\
\hline Fuel & $\mathrm{Natural} \mathrm{gas,}$ \\
\hline
\end{tabular}

An air compressor, combustion chamber, turbine, heat regenerator, and alternator are common components of MGTs. They can be operated with natural gas, biogas, associated gas, biodiesel. In the commercial Capstone C30 package (see Figure 1) the process air in the gas turbine is firstly compressed by a radial compressor (from state 1 to state 2) and further pre-heated by the annular regenerator using the hot turbine exhaust gas (from state 2 to state 2'). Micro gas turbines are capable of significantly increasing electrical efficiency using this technique at low-pressure ratios. Once in the combustion chamber (state 3 ), the process air is mixed with the fuel and burned. 
By-products of combustion are then depressurised via the expander (4), cooled by the heat regenerator (from state 4 to 4 '), and finally passed through the liquid to gas heat exchanger (from state 5 to 6 ) to generate hot water for the HVAC system. Some parameters related to the energy efficiency of MGT have been measured directly by instruments and probes, while others, especially those associated with the intermediate states, have been calculated by reverse engineering. The onboard PLC (Programmable Logic Controller) has recorded the electric power output, rotation speed, inlet temperature $T_{1}$, and combustion temperature $T_{3}$. Thus, the final exhaust gas temperature $\mathrm{T}_{6}$ has been measured by the gas analyser temperature probe, and the hot water temperature and water flow rate have been recorded by the thermal counter.

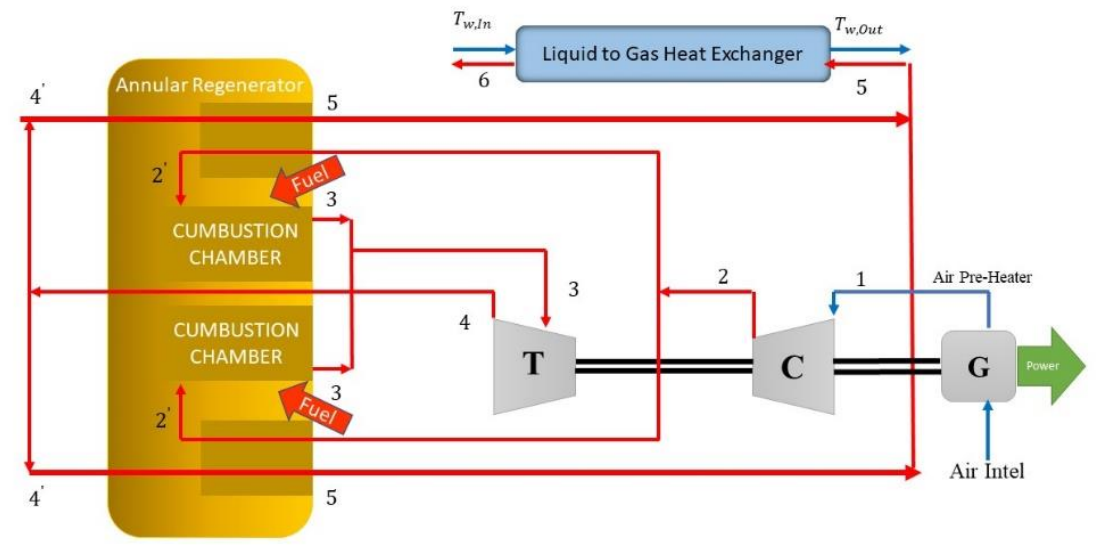

Fig. 1. Capstone C30 process layout [18].

\section{MATLAB-SIMULINK Model}

In the simulation model, MATLAB-Simulink has been used to implement all components, including compressor, recuperator, combustion chamber, and turbine. First, each of the components of the micro gas turbine was modelled, and the equations for their operation were implemented. In the second phase, we analysed and described the process system. The model is then run to evaluate the MGT's behaviour when fed $\mathrm{H}_{2} \mathrm{NG}$ blends. Calculated results are compared with experimental results.

\subsection{Compressor}

The compressor block describes the centrifugal compressor that is clamped on the same shaft as the turbo-alternator. The inputs to the subsystem are inlet temperature $\left(T_{1}\right)$,polytropic efficiency $\left(\eta_{\mathrm{pt}}\right)$, air constant $(R)$, inlet pressure $\left(p_{1}\right)$ nominal compression ratio $\left(\beta_{c}\right)$ air specific heat $(C p)$ and the outputs of the system are obtained using the equation:

$$
\begin{gathered}
\mathrm{T}_{2}=\beta_{\mathrm{c}} \mathrm{T}_{1}^{\frac{\mathrm{k}-1}{{ }_{\mathrm{pt}} * \mathrm{k}}}=\beta_{\mathrm{c}} \mathrm{T}^{\frac{\mathrm{R}}{{ }_{\mathrm{pt}}^{* \mathrm{Cp}}}} \\
\mathrm{p}_{2}=\beta_{\mathrm{c}} \mathrm{p}_{1}
\end{gathered}
$$




\subsection{Recuperator}

One of the most important and critical components of the system is the recuperator, which is a counter-flow heat exchanger in which the compressed air flow rate is preheated by the exhaust expanded gases entering the turbine. The subsystem is modelled to output the temperature reached by the air before entering the combustion chamber $\left(T_{2}^{\prime}\right)$. The inputs of the system are exhaust gas temperature of the exchanger, given by technical data sheet for each power output air temperature, approach temperature, expressed as $\left(T_{4}-T_{2}{ }^{\prime}\right)$, fixed in nominal condition to $50^{\circ} \mathrm{C}$, evaluated iterating on $T_{4}, T_{3}, \beta_{e}$, and on the exhaust flow rate in different operating conditions. Once known the variation of the approach temperature with the load (that is, with temperatures and flow rates), the efficiency of the heat exchanger can be computed. $T_{2}^{\prime}$ can be calculated using the equation:

$$
\left(\frac{1+\alpha}{\alpha}\right) \mathrm{C}_{\mathrm{p} \text { exhaust, } 4-5}\left(\mathrm{~T}_{4}-\mathrm{T}_{5}\right)=\mathrm{C}_{\mathrm{p} \text { air,2-2, }}\left(\mathrm{T}_{2}{ }^{\prime}-\mathrm{T}_{2}\right)
$$

\subsection{Combustion chamber}

According to an energy balance simulation of the combustion process, the air-tofuel ratio and the fuel energy can be determined using the following equation:

$$
(1+\alpha) C_{\text {pexhaust }, 2^{\prime}-3}\left(T_{3}-T_{2^{\prime}}\right)=L H V \eta_{\text {comb }}
$$

Where $\eta_{\text {comb }}$ is the combustion efficiency, LHV is the lower heating value of the fuel, defined as the amount of heat released by combusting a specified quantity (initially at $25^{\circ} \mathrm{C}$ ) and returning the temperature of the combustion products to $150^{\circ} \mathrm{C}$, which assumes the heat of vaporization of water in the reaction products is not recovered. This value strongly depends on the percent composition of the fuel, which is also related to the percent composition of the exhaust gas participating in the heat exchange.

\subsection{Turbine}

The data in the turbine block are nominal expansion ratio $(\beta \mathrm{e})$, reference $\left(\mathrm{T}_{3}\right)$, polytropic efficiency $\left(\eta_{\mathrm{pt}}\right)$ and the following equation is used to calculate the $\mathrm{T}_{4}$ :

$$
T_{4}=\frac{T_{3}}{\beta_{e}^{\frac{\eta_{p t}(k-1)}{k}}}=\frac{T_{3}}{\beta^{\frac{\eta_{p t} R}{C p}}}
$$

Where $\beta_{e}=\eta_{p} \beta_{c}$, with $\eta_{p}$ pneumatic efficiency, representing total pressure.

\subsection{Water-gas heat exchanger}

The heat recovery process in the MGT may be achieved using a dedicated water-gas heat exchanger. The energy balance is used to model this element. 


$$
T_{6}=T_{5}-\alpha \frac{\dot{m}_{H 2 O} \cdot c_{p, H 2 O}\left(T_{w, o u t}-T_{w, i n}\right)}{(1+\alpha) \dot{m}_{\text {air }} \cdot c_{p 5,6}}
$$

Water flow rate as well as inlet and outlet temperature are parameters set by the thermal user and thus given as input to the model. The energy balance requires the knowledge of the air mass flow rate, which is ultimately obtained from the specific useful power, using the equation:

$$
\dot{m}_{\text {air }}=\frac{P_{e l}}{\left[\frac{\left(T_{3}-T_{4}\right) c_{p 3,4}(1+\alpha)}{\alpha}-c_{p 1,2}\left(T_{2}-T_{1}\right)\right] \cdot \eta_{e l}}
$$

\section{Results and discussion}

The aim of this research is to modeling and analysis the MGT mathematical model when that machine runs in actual operating conditions, and it is fuelled Hydrogen and Natural Gas Blends.

\subsection{Validation of the model operating}

During the tests, hydrogen percentage was increased in the range of $0 \%-10 \%$ by volume in the fuel mixture with a $2 \%$ step. Thus, the MGT was experimentally characterized at medium load $(15 \mathrm{~kW})$ and at the maximum delivered electrical power achievable considering the environmental conditions, equal to $22 \mathrm{~kW}$. The electrical power measured experimentally is used as input for the model, and the simulated operative parameters are compared with those measured experimentally.

Table 2. Comparison between experimentally values and simulated in $15 \mathrm{~kW}$

\begin{tabular}{|c|c|c|c|c|c|c|}
\hline \multirow{2}{*}{$\mathbf{1 5 k W}$} & \multicolumn{5}{|c|}{$\mathbf{H}_{\mathbf{2}} \%$} \\
\cline { 2 - 7 } & $\mathbf{0} \%$ & $\mathbf{2} \%$ & $\mathbf{4} \%$ & $\mathbf{6 \%}$ & $\mathbf{8} \%$ & $\mathbf{1 0} \%$ \\
\hline $\mathbf{T}_{\mathbf{3}}$ Simulated & 1052.36 & 1051.66 & 1050.34 & 1050.09 & 1050.24 & 1049.52 \\
\hline $\mathbf{T}_{\mathbf{3}}$ Measurements & 1052 & 1051 & 1051 & 1050 & 1050 & 1049 \\
\hline Error \% & 0.0339 & 0.0627 & 0.0628 & 0.0083 & 0.0231 & 0.0500 \\
\hline $\mathbf{T}_{\mathbf{4}}$ Simulated & 868.164 & 868.164 & 868.164 & 868.164 & 868.164 & 868.164 \\
\hline $\mathbf{T}_{\mathbf{4}}$ Measurements & 865.044 & 865.156 & 864.737 & 864.4 & 864.462 & 864.362 \\
\hline Error \% & 0.3594 & 0.3464 & 0.3947 & 0.4336 & 0.4264 & 0.4379 \\
\hline $\mathbf{T}_{2}$ Simulated & 449.92 & 449.94 & 449.92 & 449.96 & 449.92 & 449.91 \\
\hline $\mathbf{T}_{\mathbf{2}}$ Measurements & 450.133 & 449.484 & 449.918 & 450.446 & 450.996 & 450.235 \\
\hline Error \% & 0.0925 & 0.0041 & 0.0518 & 0.2435 & 0.0518 & 0.0744 \\
\hline
\end{tabular}


Table 3. Comparison between experimentally values and simulated in $22 \mathrm{~kW}$

\begin{tabular}{|c|c|c|c|c|c|c|}
\hline \multirow{2}{*}{2} & \multicolumn{5}{|c|}{$\mathbf{H}_{\mathbf{2}} \%$} \\
\cline { 2 - 7 } & $\mathbf{0} \%$ & $\mathbf{2} \%$ & $\mathbf{4} \%$ & $\mathbf{6} \%$ & $\mathbf{8} \%$ & $\mathbf{1 0} \%$ \\
\hline T3 Simulated & 1074 & 1074 & 1075 & 1075 & 1075 & 1073 \\
\hline T3 Measurements & 1073.62 & 1074.57 & 1074.18 & 1074.69 & 1075.91 & 1073.57 \\
\hline Error \% & 0.0539 & 0.0758 & 0.0289 & 0.0849 & 0.0849 & 0.0534 \\
\hline T4 Simulated & 868.164 & 846.961 & 868.164 & 868.164 & 868.164 & 868.164 \\
\hline T4 Measurements & 865.04 & 846.30 & 846.43 & 846.46 & 846.22 & 846.23 \\
\hline Error \% & 0.0574 & 0.0781 & 0.0626 & 0.0582 & 0.0899 & 0.0855 \\
\hline T2 Simulated & 488.51 & 488.52 & 488.51 & 488.52 & 488.51 & 488.52 \\
\hline T2 Measurements & 487.13 & 489.35 & 488.30 & 488.82 & 489.30 & 488.85 \\
\hline Error \% & 0.278 & 0.176 & 0.039 & 0.066 & 0.164 & 0.073 \\
\hline
\end{tabular}

According to the results, the maximum error in both simulations (minimum load and maximum load achievable) is lower than the uncertainty in measurements.

\subsection{Modeling of the operation of the MGT fuelled with $\mathrm{H}_{2} \mathrm{NG}$ blends}

The addition of $\mathrm{H}_{2}$ results in an increasing lower heating value by mass, but because $\mathrm{T}_{4}$ and the expansion ratio are set for each speed and power, the Turbine Inlet Temperature (TIT) results are almost constant, with only the variation of the specific heat and the gas constant affecting the TIT. 


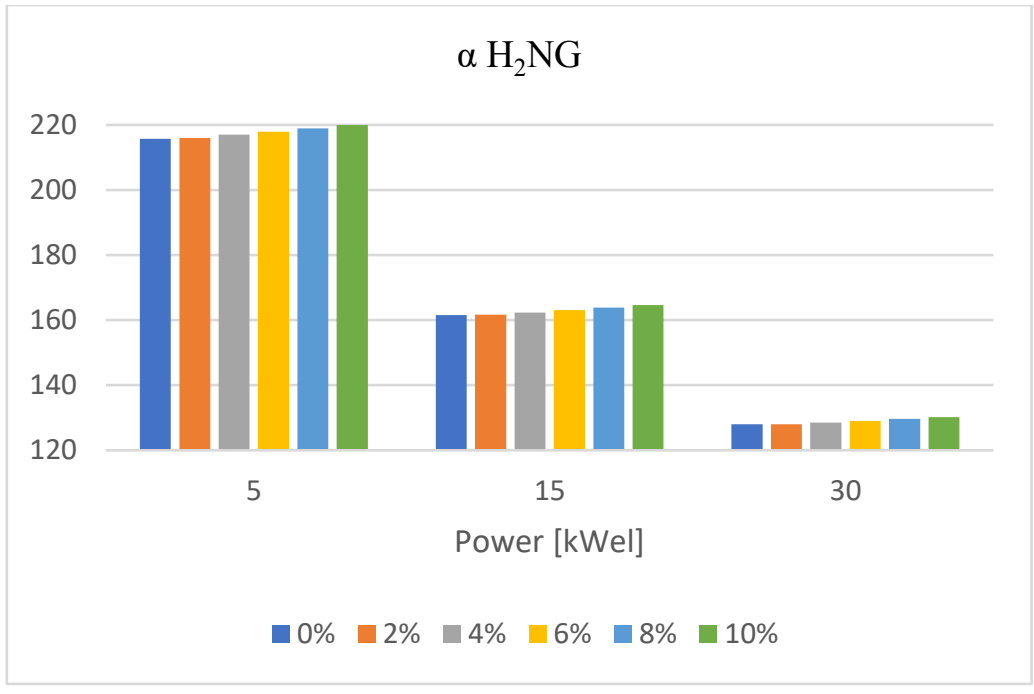

Fig. 2. Variation of air to fuel ratio with $\mathrm{H}_{2} \%$ at 5,15 and $30 \mathrm{kWel}$

Consequently, Figures 3 and 4 show that the air flow rate increases somewhat while fuel consumption decreases.

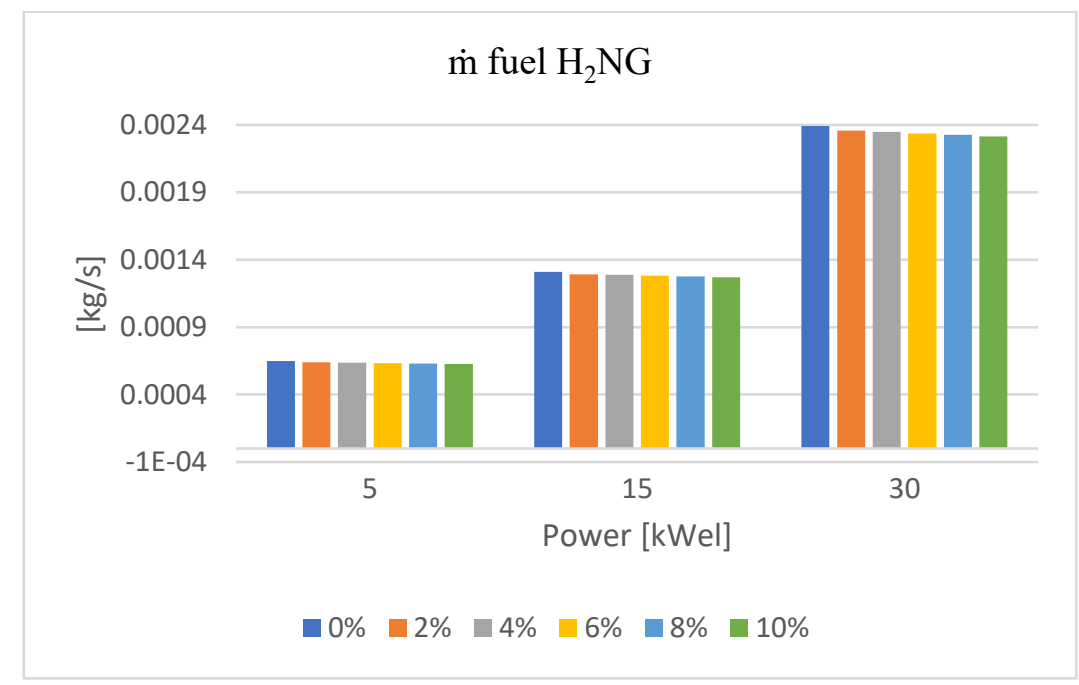

Fig. 3. Variation of fuel mass flow rate with $\mathrm{H}_{2} \%$ at 5,15 and $30 \mathrm{kWel}$ 
The lower heating value of the blends requires less fuel to produce the same quantity of heat in a combustion process.

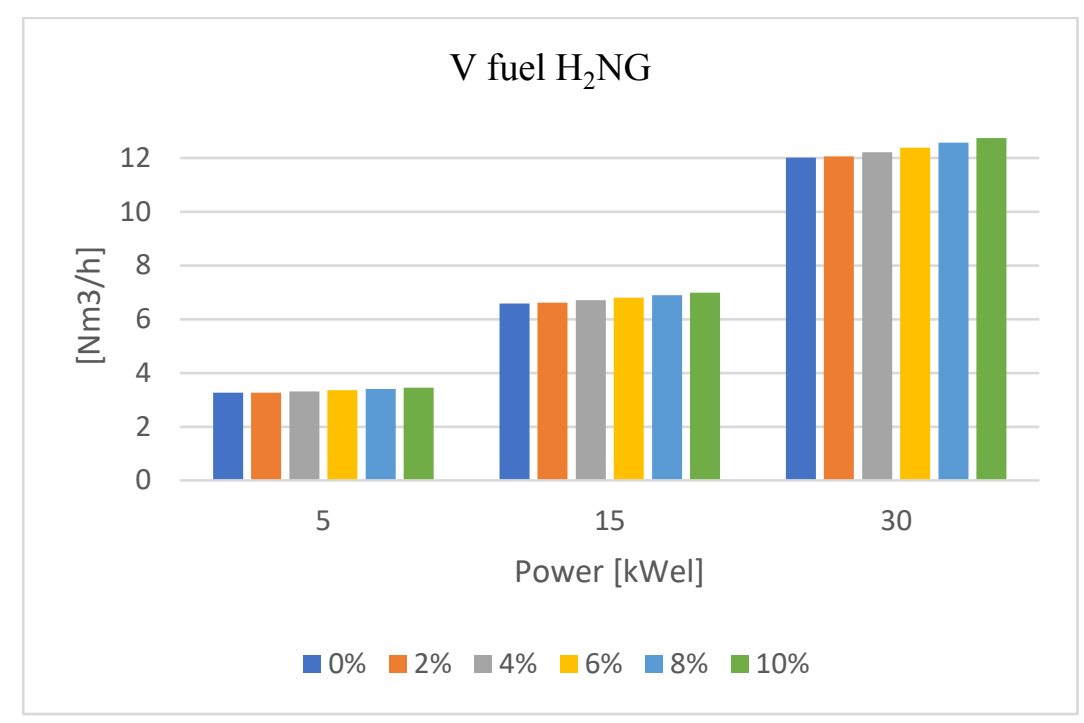

Fig.4. Variation fuel Volumetric flow rate with $\mathrm{H}_{2} \%$ at 5,15 and $30 \mathrm{kWel}$

$\mathrm{T}_{2}, \mathrm{~T}_{3}$, and $\mathrm{T}_{5}$ show no significant changes. In addition to this finding, the same trend was also observed during the experimental campaign. This means that to reach the same enthalpy difference between $T_{3}$ and $T_{4}$, less fuel is needed when lower heating value is higher. In contrast, the expansion ratio may go up along with TIT because of the energy released in combustion. If this occurred, maximum TIT and maximum compression ratio would be achieved at a lower speed, so nominal power output would not be achieved. Figure 5 shows that the electrical efficiency increases slightly due to the lower fuel consumption, which counteracts the increase in the lower heating value. 


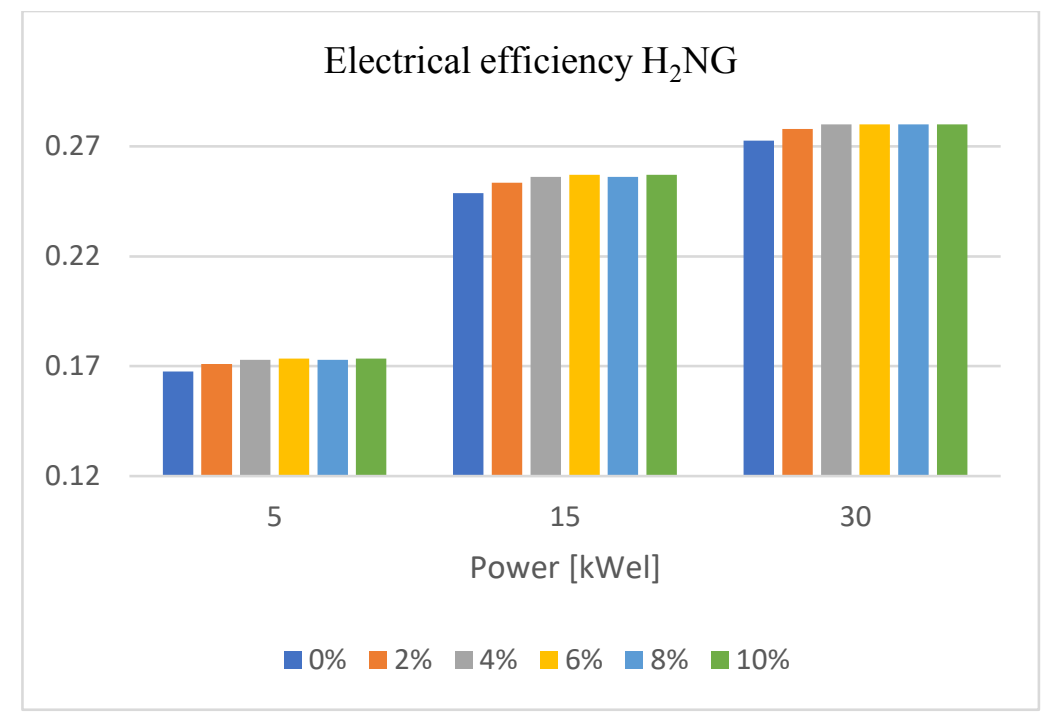

Fig.5. Variation electrical efficiency with $\mathrm{H}_{2} \%$ at 5,15 and $30 \mathrm{kWel}$

The addition of up to $10 \% \mathrm{H}_{2}$ to the mixture does not significantly affect the behaviour of the micro gas turbine, but that performance can even increase, though by a small percentage (maximum of nearly 0.01 ). In addition, it's evident that the heat recovery efficiency also follows the same trend, since thermal power depends greatly on waterside parameters, and doesn't change as much with small changes in exhaust flow rate. In figure 6 is shown the heat recovery efficiency with the hydrogen content in the mixture at 5,15 and $30 \mathrm{~kW}$.

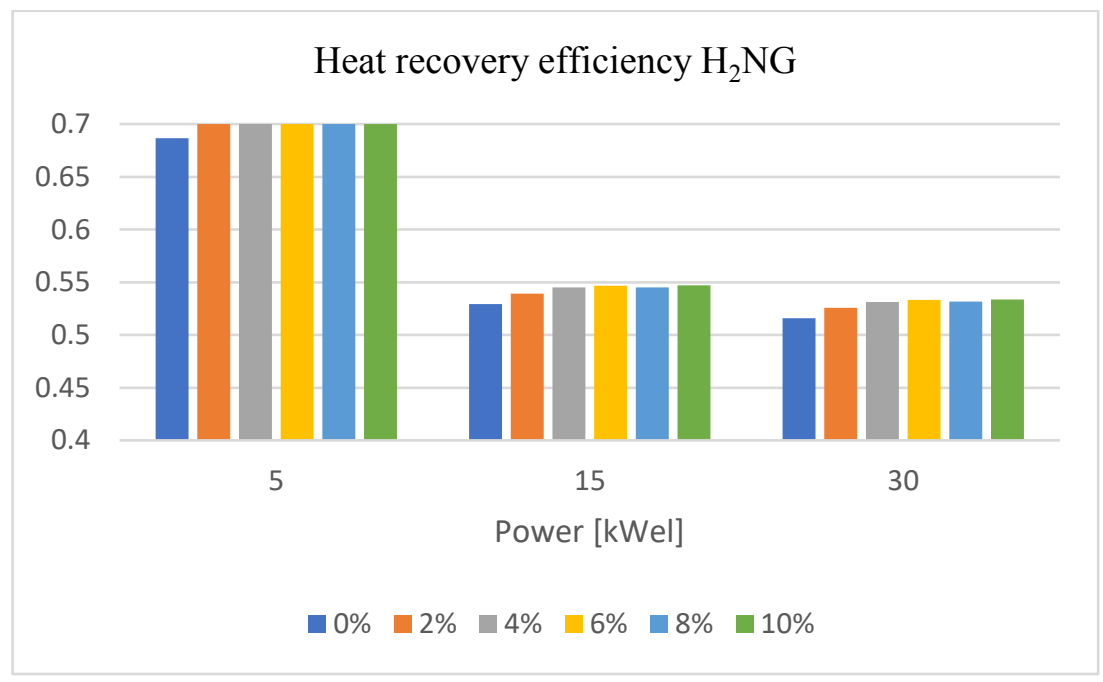

Fig. 6. Variation heat recovery efficiency with $\mathrm{H}_{2} \%$ at 5,15 and $30 \mathrm{kWel}$ 


\section{Conclusions}

The present research illustrates the modeling and analysis of a $30 \mathrm{kWel} \mathrm{micro} \mathrm{gas}$ turbine when fed with Hydrogen and Natural Gas blends with increasing percentage of hydrogen in the range of $0-10 \%$ by volume with a $2 \%$ step. In this work, a numerical model based on MATLAB-Simulink is used to simulate the operation of the MGT. Simulations are compared with their technical datasheets and the data from experimental campaigns to confirm that the model is valid for real- operations. The maximum relative error between the simulated and reference values is $1.4 \%$. To verify the accuracy of the model, While the cycle parameters are not affected by the addition of hydrogen, the fuel consumption is significantly reduced. Using up to $10 \%$ $\mathrm{H}_{2}$ to the mixture does not significantly alter the behaviour of the micro gas turbine, but even improves its performance.

\section{References}

1. European Commission 2018-2020 Climate and energy package.

2. Ministry of economic development and the Ministry of the environment and protection of the territory of the sea, National Energy Strategy (SEN) (10 November 2017).

3. European Commission 2030 Climate and energy framework available at: https://ec.europa.eu/clima/policies/strategies/2030_en

4. L. Wei, P. Geng, A review on natural gas/diesel dual fuel combustion emissions and performance Fuel Process Technol, 142 (2016), pp. 264-278.

5. W. Kreuter, H. Hofmann, the important energy transformers in a world of sustainable energy Int J Hydrogen Energy (1998), pp. 661-666.

6. Hsin-Yi Shih, Chi-Rong Liu, A computational study on the combustion of hydrogen/methane blended fuels for a micro gas turbine Int J Hydrogen Energy, 39 (2014), pp. 15103-15115.

7. HouXin Xiao Sen, Zhang Zhun, QingHu, Experimental and numerical study on engine fueled with different fractions of natural gas-carbon dioxide-hydrogen blends Int J Hydrogen Energy, 44 (11) (26 February 2019), pp. 5599-5606.

8. M. Cadorin, M. Pinelli, A. Vaccari, R. Calabria, F. Chiariello, P. Massoli, E. Bi anchi Analysis of a micro gas turbine fed by natural gas and synthesis gas: MGT test bench and combustor CFD analysis J Eng Gas Turbines Power, 134 (7) (2012), Article 071401.

9. Marco Antonia Rosa Do Nascimento, Lucilene De Oliveira Rodrigues, Eraldo Cruz dos Santos, Eli Eber Batista Gomes, Micro gas turbine engine, A review www.intechopen.com 
10. Nicola Constrisciani ENEA, Hydro methane sustainability and market opportunities (April 2009).

11. Xu, J., Zhang, X., Zheng, S.-Z., Liu, J.-H., Experimental on combustion stability in an engine fueled with biogas and hydrogen blends, Neiranji Xuebao/Trans CSICE (Chin Soc Intern Combust Engines) 29(3), pp. 236-240.

12. P. Rajpara, R. Shah, J. Banerjee, Effect of hydrogen addition on combustion and emission characteristics of methane fuelled upward swirl can combustor Int J Hydrogen Energy, 43 (2018).

13. C. Altantzis, C.E. Frouzakis, A.G. Tomboulides, Detailed numerical simulations of intrinsically unstable two-dimensional planar lean premixed hydrogen/air flames Proc Combust Inst, 1 (2011), pp. 1261-1268.

14. S. Ouchikha, M.S. Lounicia, L. Tarabetb, K.LoubarcM. Tazeroutc, Effect of natural gas enrichment with hydrogen on combustion characteristics of a dual fuel diesel engine Int J Hydrogen Energy, 142 (2016), pp. 264-278.

15. A. Cappelletti, F. Martelli, E. Bianchi, Trifoni, Numerical redesign of 100kw MGT combustor for $100 \%$ H2 fueling, 45, Energy Procedia (2014), pp. 14121421.

16. Livio De Santoli, Gianluigi Lo Basso, Daniele Bruschi, Preliminary experimental analysis of a CHP hydro methane system, J Energy Power Eng, 7 (2013), pp. 1681-1690.

17. Gianluigi Lo Basso, Livio De Santoli, Albo Angelo, Benedetto Nastasi, $\mathrm{H}_{2} \mathrm{NG}$ (hydrogen-natural gas mixtures) effects on energy performances of a condensing micro-CHP (combined heat and power) for residential applications: an expeditious assessment of water condensation and experimental analysis Energy, 84 (2015), pp. 397-418

18. De Santoli, L., Lo Basso, G., Barati, S., D'Ambra, S., Fasolilli, C,Seasonal energy and environmental characterization of a micro gas turbine fueled with $\mathrm{H}_{2} \mathrm{NG}$ blends Energy, (2020), 193, 116678.

19. Guglielmo Magri, Costanzo Di Perna Giorgio Serenelli, Analysis of electric and thermal seasonal performances of a residential micro-CHP unit Appl Therm Eng, 36 (April 2012), pp. 193-201 1359-4311.

20. M.C. Lee, S. Bin Seo, J.H. Chung, S.M. Kim, Y.J. Joo, D.H. Ahn, Gas turbine combustion performance test of hydrogen and carbon monoxide synthetic gasFuel, 89 (7) (2010), pp. 1485-1491.

21. A.R. Khan, M.R. Ravi AnjanRay, Experimental and chemical kinetic studies of the effect of $\mathrm{H}_{2}$ enrichment on the laminar burning velocity and flame stability 
of various multicomponent natural gas blends Int J Hydrogen Energy, 44 (2) (8 January 2019), pp. 1192-1212.

22. M.S. Lounici, A. Boussadi, K. Loubar, Tazerout, Experimental investigation on NG dual fuel engine improvement by hydrogen enrichment Int J Hydrogen Energy, 36 (2014), p. 21297.

23. Aqiang Lin, Qun Zheng, Yuting Jiang, Lin Xiang, Hai Zhang, Sensitivity of air/mist non-equilibrium phase transition cooling to transient characteristics in a compressor of gas turbine Int J Heat Mass, 137 (2019), 